\title{
HIGHLY PATTERNED PRIMARY SUCCESSION AFTER FLUVIAL DEPOSITION OF MINING WASTE
}

\author{
NINA NIKOLIĆ*1 \\ ${ }^{1}$ Institute for Multidisciplinary Research, University of Belgrade, Belgrade, Serbia
}

\begin{abstract}
This study examined early stages (3-5 years) of spontaneous primary vegetation succession on a model locality drastically altered by long term fluvial deposition of copper tailings in Eastern Serbia. In a large-scale survey, 115 samples of herbaceous vegetation (with a total of 75 species) were harvested from standardized $1 \mathrm{~m} \times 1 \mathrm{~m}$ quadrates, and concomitant soil samples collected and their relevant physicochemical properties analysed. Primary succession depended on the establishment of five pioneer species (Rumex acetosella, Agrostis capillaris, Calamagrostis epigeios, Persicaria lapathifolia and Chenopodium botrys). Unconstrained ordination showed very clear vegetation gradients, significantly correlated with the key soil constraints (from $\mathrm{Cu}$ excess to low pH and nutrient deficiency), while the distribution of the five edificatory pioneers showed high degree of dependence on the micro-level habitat conditions. This work demonstrates that in such a complex setup with severe abiotic filtering, sufficient sampling effort can reveal strong patterns in a process commonly considered very stochastic.
\end{abstract}

Keywords: Copper, Gradient analysis, Habitat Modeling, Primary Vegetation Succession.

\section{INTRODUCTION}

Even after a century of research, primary succession (especially in its early stages) is in general still considered an inherently stochastic process with extremely low predictability (Buma et al., 2019). Thorough understanding of vegetation succession (a species change over time in the broadest sense) is however a key issue for sustainable restoration and management, particularly on fragile post-mining land (Prach \& Walker, 2011). Mining of metals has so far irreversibly destroyed about $1 \%$ of the global terrestrial area (Walker, 1999). Mining of sulphidic copper $(\mathrm{Cu})$ deposits creates more waste than mining of any other metal; this waste (tailings slurry) has an extremely high potential for oxidative weathering, soil acidification and metal mobilization. In fact, low $\mathrm{pH}$ and high concentrations of plant available metals can become an insurmountable obstacle for de novo establishment of vegetation (via primary succession) on such land (Bradshaw, 1997). An immanently irregular spatial distribution of soil constraints on post-mining areas (over distances shorter than $10 \mathrm{~m}$, e.g. Néel et al., 2003) further makes a gradient analysis very difficult. Notwithstanding the notion that barren post-mining landscapes provide a unique and exciting opportunity to study primary succession, (e.g. Wiegleb \& Felinks, 2001; Felinks \& Wiegand, 2008), such investigations are still worldwide very scarce.

This study examines early stages (3-5 years) of primary succession spontaneously initiated upon mine closure on a model locality in Eastern Serbia, created by long-term fluvial deposition of sulphidic $\mathrm{Cu}$ tailings over arable land. The objective is to check whether extensive sampling of soil and vegetation can

\footnotetext{
* Corresponding author: nina@imsi.bg.ac.rs BIOLOGY
}

discern any patterns which elucidate the distribution of major early plant assemblages over the very heterogeneous and drastically altered land.

\section{MATERIALS AND METHODS}

Research locality

The exclusive model locality of this study (Fig. 1) has been created during about 70 years of fluvial deposition of sulphidic $\mathrm{Cu}$ tailings waste from the Bor Copper Mine complex in Eastern Serbia. In brief, the toxic slurry from the tailing ponds was being released directly into the local river system, carried to the Timok river and deposited (via lateral accretion during regular floods) in the Timok floodplain, over the former arable land. The depth of the deposited sediments ranges from tens of $\mathrm{cm}$ to over a meter. Due to highly dynamic flooding regime, a complex mosaic of soil constraints ranging from extreme $\mathrm{Cu}$ toxicity to severe nutrient deficiency and low $\mathrm{pH}$ was created. About $80 \mathrm{~km}$ of waterways was affected and more than 10,000 ha of alluvial land is still without vegetation. For details see Nikolic et al. (2018).

\section{Vegetation sampling}

The major sampling sites were located along about $30 \mathrm{~km}$ of the Timok flow (Fig. 1), where the river slowly meanders and creates a braided pattern of smaller lateral channels. The sampling design comprised firstly stratification according to the dominant pioneer species followed by flexible systematic sampling according to the visual appearance of the vegetation (Smartt, 1978). Aboveground biomass was harvested from standardized $1 \mathrm{~m}$ x $1 \mathrm{~m}$ quadrates, separated by species, air dried and used for further analyses. All the samples were less than 300 $\mathrm{m}$ away from the riverbed or seasonally dry lateral channel; our 
larger monitoring study guaranteed that the relevées were of the age of 3 to 5 years.

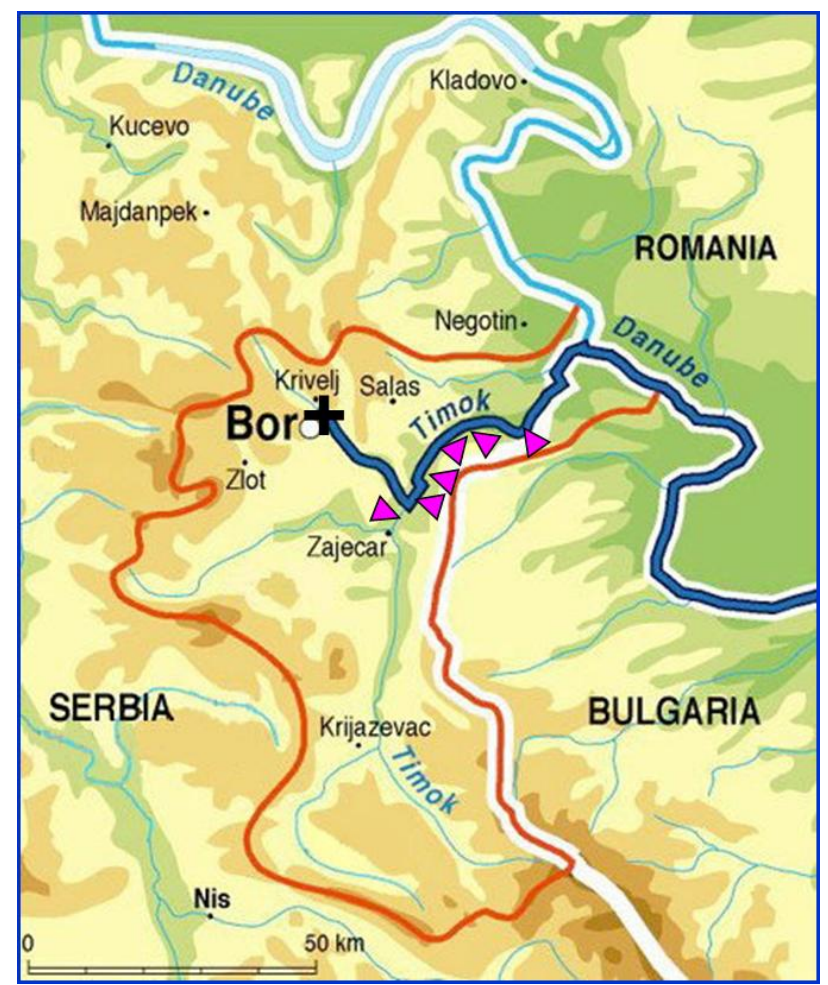

Figure 1. Study area. Red line denotes the Timok watershed, black cross marks the ore flotation facilities and the leaking tailing ponds. Polluted waterways are emphasized in dark blue, while purple triangles mark the major research sites.

\section{Soil sampling and analyses}

In each vegetation sample (quadrate) a composite soil sample (consisting of 3 subsamples) was taken at the rooting depth $(0-20 \mathrm{~cm})$, and analysed for 21 chemical and physical parameters (for details see Nikolic \& Nikolic, 2012). Plant available concentrations of mineral elements were determined by different extractions: DTPA for metals, ammonium acetateammonium lactate ( $\mathrm{AL}$ ) for $\mathrm{P}$ and $\mathrm{K}$, and $\mathrm{KCl}$ for $\mathrm{Al}$.

\section{Statistical analyses}

Prior to ordination, biomass data were log-transformed by using the generalized $\log$ transform formula $[b=\log (x+x m i n)-$ $\log (\mathrm{xmin})]$ to deal with zeroes. Biomass is a more precise measure than other common abundance indices. The unconstrained ordination (ordering of sampling units on the basis of vegetation data according to the covariation and association among the species) was done by Nonmetric Multidimensional Scaling (NMS), a robust non-parametric method based on rank distances. Soil data were passively projected (overlaid) on the ordination scores to produce joint plot. NMS was done using the PC-ORD 6.22 software (MjM Software Design, Gleneden Beach, USA). Variation in performances of the five edificatory pioneer species was related to the measured soil parameters using habitat models. Multiplicative habitat modeling was done by Non-Parametric Multiplicative Regression (NPMR) with the HyperNiche 2.3 software (MjM Software Design, Gleneden Beach, USA). NPMR was performed using Local Mean with a Gaussian weighting function; species response matrix contained biomass data relativized by total plot DW. Conservative overfitting control, better suited for the clumped data, was applied. Best soil predictors were selected for the highest tolerance and cross-validated pseudo- $\mathrm{R}^{2}$.

\section{RESULTS AND DISCUSSION}

The natural revegetation process on this locality depends on the arrival and establishment of the five keystone pioneers (Fig. 2). These species are: perennial rhizomatous grasses Agrostis capillaris L. and Calamagrostis epigeios (L.) Roth, a perennial forb with strong vegetative propagation Rumex acetosella $\mathrm{L}$. (Polygonaceae), and two therophytes (annuals), Persicaria lapathifolia (L.) Gray (Polygonaceae) and Chenopodium botrys L. (Chenopodiaceae). Of these five, only P. lapathifolia occurs but never dominates in the referent, pre-pollution natural vegetation of the study area (alluvial poplar forests of the Populion albae Br.-B1. 1931 alliance), and only C. epigeios occassionaly occurs in a matrix of xerothermic calcicole vegetation surrounding the affected floodplain (to a distance of at least $5 \mathrm{~km}$ ). Our other long-time monitoring shows that if any of the keystone pioneers (except Calamagrostis) would not get established, certain (well defined) patches would remain barren and the succession arrested (Nikolic, 2014)

Over the initial period (3-5 years) the keystone pioneers act as facilitators of the primary succession, allowing the gradual immigration of the accompanying 70 species, increase in biomass production and in biodiversity (Table 1). These are mostly pseudometallophytes (many are ruderals), about $27 \%$ of which are shared among the five assemblages. High and fluctuating number of species, and unusual and unstable species compositions ("Frankenstein" assemblages) like those encountered here, are typical for very early stages of primary succession, in particular on man-made habitats (e.g. Tischew \& Kirmer, 2007).

Unconstrained ordination (Fig. 3.) shows three strong gradients which capture $83 \%$ of variation in these early vegetation stands. The gradients in species composition of the early vegetation are significantly correlated with the measured soil parameters. The strongest separation of the early vegetation samples (stands dominated by $R$. acetosella, A. capillaris and $P$. lapathifolia, against the stands of Ch. botrys and $C$. epigeios) occurs along the first two ordination axes, which are correlated with the two main soil gradients: increasing soil $\mathrm{pH}$, phosphorus $(\mathrm{P}), \mathrm{Cu}$ vs increasing aluminum $(\mathrm{Al})$ and iron $(\mathrm{Fe})$ concentrations along the Axis 2; and increasing potassium (K), total nitrogen $\left(\mathrm{N}_{\text {tot }}\right)$ and organic carbon $\left(\mathrm{C}_{\text {org }}\right)$ along the Axis 1 (Fig. 3). On the other hand, NMS Axis 3 captures significant variation in 
vegetation data, but is only weakly (Pearson's correlation coefficient of only 0.12 ) correlated with the single soil parameter, total sulphur $\left(\mathrm{S}_{\mathrm{tot}}\right)$ concentration in soils. This parameter (which, per se, has no direct effect on plant growth) was previously shown to be a good indicator of the amount of pollution deposited in the research area, and to be highly correlated with the development of later successional forest vegetation (Nikolic et al., 2016, 2018), and even with the weed vegetation in partially polluted but still cropped fields at the outer edge areas of the polluted alluvium (Nikolic et al., 2014). This indicates that micro-scale patterning (sometimes over the distances of only a few meters) of soil constraints is decisive for the very early primary succession, but that a more "coarser scaled" behavior could be expected along the spatial pollution gradients in the lather stages. It is commonly not feasible to include such tiny variations into the sampling design (Néel et al., 2003), what contributes to the increased "randomness" of this early process.

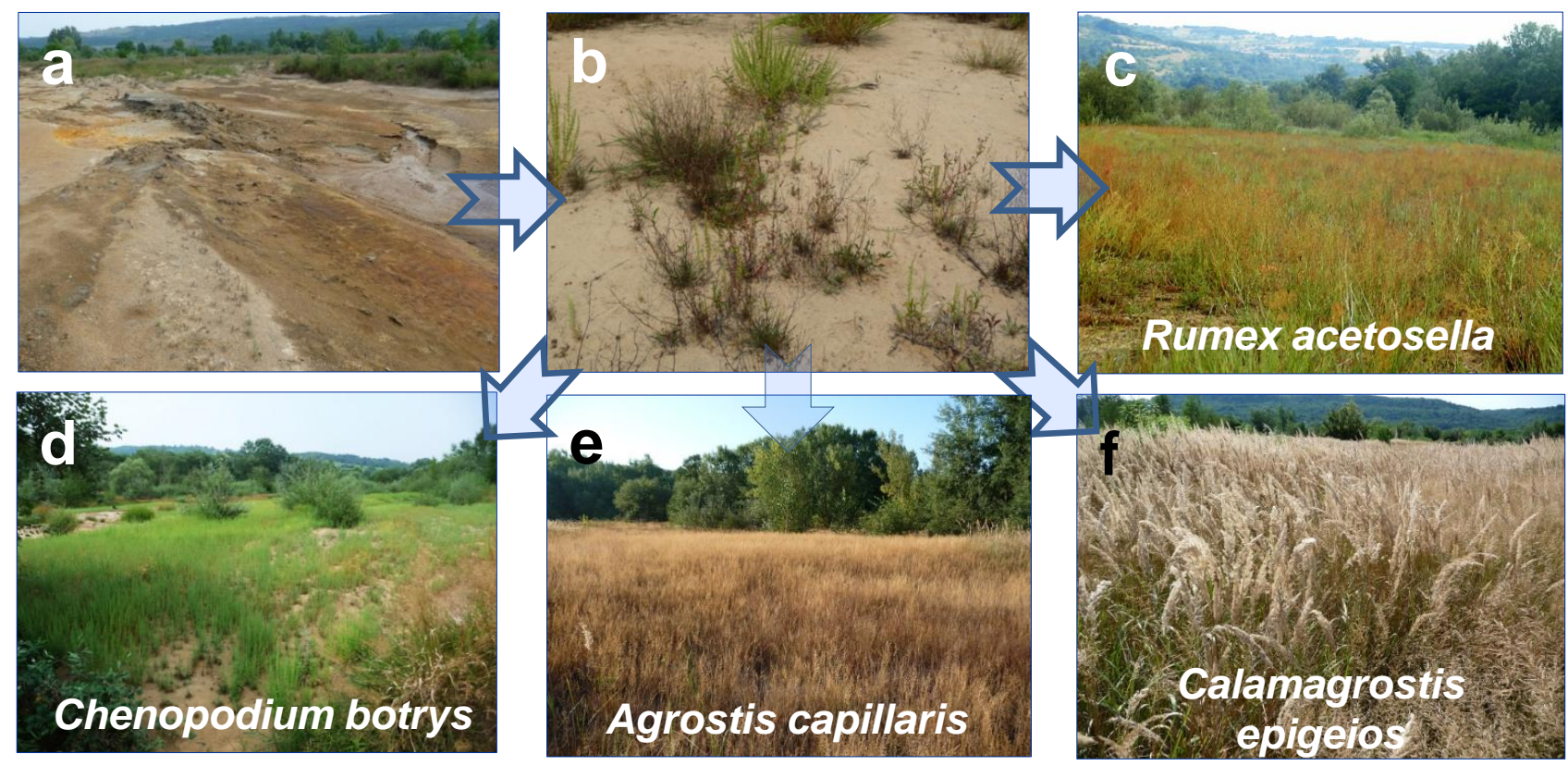

Figure 2: Primary succession on the barren land polluted by mining effluents in the Timok floodplain (a) does not start without five keystone pioneer species: Rumex acetosella, Agrostis capillaris, Persicaria lapathifolia and Chenopodium botrys (b). Their niches broadly overlap, but each achieves dominance (c-f) at distinct sections of the soil gradient. "Dominance" refers to about $50 \%$ of the biomass per $\mathrm{m}^{2}$.

Table 1: Overview of the major 5 types of pioneer vegetation on the barren land polluted by the fluvially deposited Cu tailings. Edificatory species: A - Rumex acetosella; B - Agrostis capillaris; C - Persicaria lapathifolia; D - Chenopodium botrys; ECalamagrostis epigeios.

\begin{tabular}{|c|c|c|c|c|c|}
\hline \multirow{2}{*}{ Parameters } & \multicolumn{5}{|c|}{ Pioneer vegetation dominated by: } \\
\hline & A & $\mathrm{B}$ & $\mathrm{C}$ & $\mathrm{D}$ & $\mathrm{E}$ \\
\hline No. of samples & 27 & 31 & 17 & 20 & 20 \\
\hline Total species no. & 64 & 62 & 38 & 40 & 65 \\
\hline Average species no. per $\mathrm{m}^{2}$ & 9.4 & 8.0 & 7.8 & 6.7 & 14.0 \\
\hline Average aboveground biomass ( $\mathrm{g} \mathrm{DW} \mathrm{m}^{-2}$ ) & 184 & 199 & 173 & 83 & 547 \\
\hline Average within-group distance (Sørensen) ${ }^{\mathrm{a}}$ & 0.53 & 0.46 & 0.47 & 0.50 & 0.37 \\
\hline
\end{tabular}

${ }^{a}$ group is defined by the dominant pioneer specie 


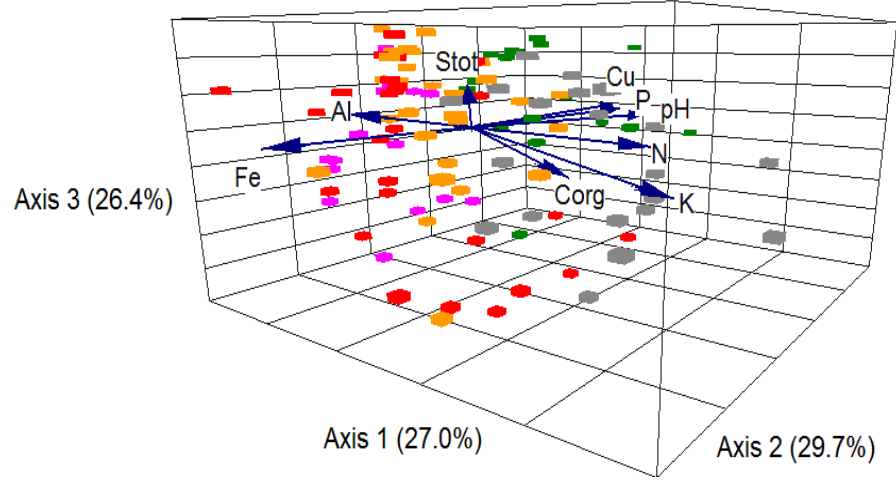

Figure 3: Unconstrained ordination (Nonmetric Multidimensional Scaling, NMS) of early vegetation relevées dominated by one of the five pioneer species occurring on the polluted floodplain. Selected soil parameters (plant available fractions of $\mathrm{P}$ and metals, and total concentrations of $\mathrm{N}$ and Corg), correlated with the ordination scores by $>10 \%$, are overlaid. The values in parenthesis denote the proportion of variance represented by each axis. The angles and lengths of the radiating lines indicate the direction and strength of relationships of the soil variables with the ordination scores. Data matrix: 75 species, 115 stands, log-transformed biomass data, Sørensen distance, varimax rotation; final stress for 3-d solution 14.52 . Assemblages dominated by each key pioneer are colour coded: red - R. acetosella; orange - A. capillaris; purple - $P$. lapathifolia; grey-C. epigeios; green - Ch. botrys.

Though the ordination of early vegetation shows very strong gradients, the Pearson's correlation coefficient of ordination with the measured soil parameters ranges from 0.12 to about 0.4 . This might not be sufficient to clearly predict the occurrence of certain assemblages, but it is more of correlation than so far reported (e.g. Wiegleb \& Felinks, 2001). On the other hand, the separation of preferred habitats of the keystone pioneers (modeled distribution along the gradient of soil constraints) is much clearer (Fig. 4). Putting together the data of this study, certain trends can be discerned:

1. P. lapathifolia and Ch. botrys-dominated patches occupy the smallest area and have the lowest biomass production; the former prefers microsites with stagnating water (low sand content), while the latter is a weak competitor which avoids acidic sites and thrives on $\mathrm{Cu}$ rich outcrops where other species are excluded by extreme $\mathrm{Cu}$ availability (median about $300 \mathrm{mg} \mathrm{kg}^{-1}$ of DTPA-extractable $\mathrm{Cu}$ ).

2. Calamagrostis-dominated stands produce most biomass, and facilitate the establishment of the highest number of immigrating species. Calamagrostis avoids wet habitats (with higher availability of $\mathrm{Fe}$ ), occurs with the increased incidence of uncontrolled burning (from the neighbouring crop fields - indicated by high $\mathrm{K}$ availability in soils), and generally prefers nutrient richer soils.
3. R. acetosella and A. capillaris dominate the landscape. They establish on nutrient poor, acidic and moist microsites, and are competitively excluded from more fertile sites.

\section{Rumex acetosella}

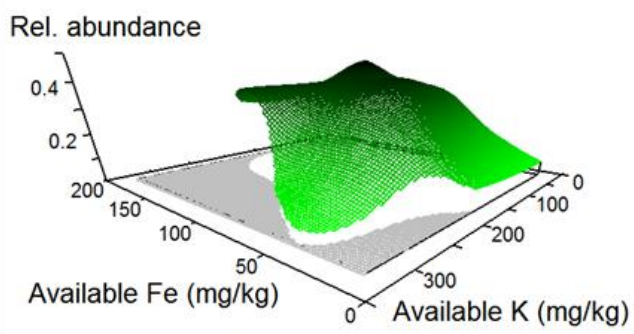

Agrostis capillaris
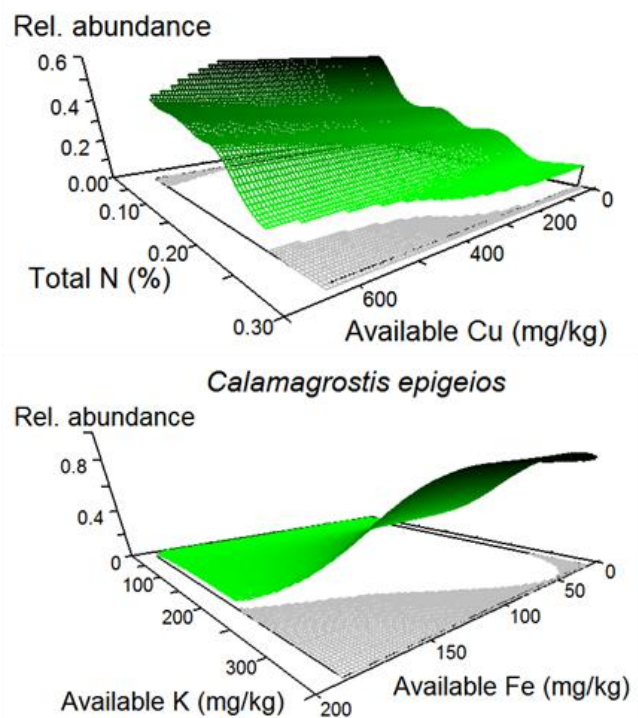

Persicaria lapathifolia

Rel. abundance

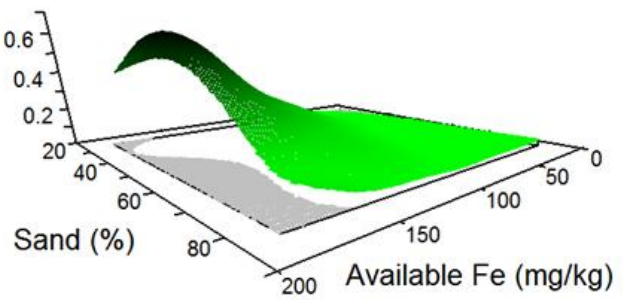

Chenopodium botrys

Rel. abundance

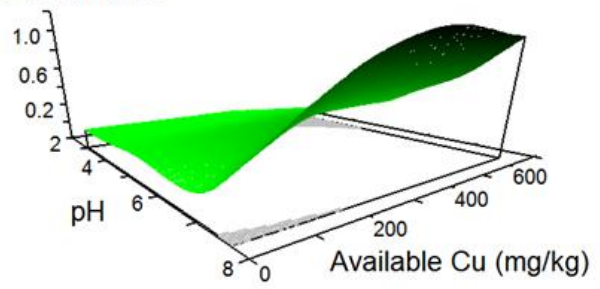

Figure 4: Habitat modeling (responses of the pioneers to the key soil parameters) by Non-Parametric Multiplicative Regression (NPMR). Relative abundance - share of the species in the total aboveground DW per $\mathrm{m}^{2}$, analysed across 115 relevées. Best soil predictors are shown. 
In general, the results of this study imply that a stronger correlation between vegetation establishment and soil constraints is found for single pioneer species, and then for the subsequent assemblages created around these edificatory species just a couple of years later. We recognize that our keystone species act as "nuclei" to facilitate further colonization. This is principally in accordance with the baseline findings of Felinks \& Wiegand (2008), that facilitation processes influence spatial patterns of early primary succession only on short-term temporal and very fine spatial scales. Moreover, of the 115 samples examined, we never found any other species but the five aforementioned keystone species to appear in a share of more than $10 \%$ in the biomass per $\mathrm{m}^{2}$ (what is five time less than the share of these five "greats" in their respective assemblages). We believe that the extremely harsh abiotic filtering, imposed by drastic alteration by pollution deposition (for details on soil constrains see Nikolic et al., 2014, 2016, 2018), is responsible for a clear response patterns obtained (Figs. 3 and 4), what can be expected in early primary succession on man-made land (Walker \& delMoral, 2003).

\section{CONCLUSION}

Very early stages of primary succession are difficult to predict. Yet, we could demonstrate that the establishment of keystone pioneer species, which facilitate further vegetation development, is closely related to the micro-scale variability of soil constraints, and thus not random. Our results should, in a long run, contribute to improving the linkage of ecological theory with restoration practice.

\section{REFERENCES}

Bradshaw, A. 1997. Restoration of mined lands - using natural processes. Ecological Engineering, 8(4), pp. 255-269. doi:10.1016/s0925-8574(97)00022-0

Buma, B., Bisbing, S. M., Wiles, G., \& Bidlack, A. L. 2019. $100 \mathrm{yr}$ of primary succession highlights stochasticity and competition driving community establishment and stability. Ecology, 100(12). doi:10.1002/ecy.2885

Felinks, B., \& Wiegand, T. 2008. Exploring spatiotemporal patterns in early stages of primary succession on former lignite mining sites. Journal of Vegetation Science, 19(2), pp. 267-276. doi:10.3170/2008-8-18369

Néel, C., Bril, H., Courtin-Nomade, A., \& Dutreuil, J. 2003. Factors affecting natural development of soil on 35-year-old sulphide-rich mine tailings. Geoderma, 111(1-2), pp. 1-20. doi:10.1016/s0016-7061(02)00237-9
Nikolic, N., \& Nikolic, M. 2012. Gradient analysis reveals a copper paradox on floodplain soils under long-term pollution by mining waste. Science of The Total Environment, 425, pp. 146-154. doi:10.1016/j.scitotenv.2012.02.076

Nikolic, N., Böcker, R., Kostic-Kravljanac, L., \& Nikolic, M. 2014. Assembly Processes under Severe Abiotic Filtering: Adaptation Mechanisms of Weed Vegetation to the Gradient of Soil Constraints. PLoS ONE, 9(12) doi:10.1371/journal.pone.0114290

Nikolic, N. 2014. Ecology of alluvial arable land polluted by copper mine tailings. Saarbruecken: SVH.

Nikolic, N., Böcker, R., \& Nikolic, M. 2016. Long-term passive restoration following fluvial deposition of sulphidic copper tailings: Nature filters out the solutions. Environmental Science and Pollution Research, 23(14), pp. 13672-13680. doi:10.1007/s1 1356-015-5205-0

Nikolic, N., Kostic, L., \& Nikolic, M. 2018. To dam, or not to dam? Abolishment of further flooding impedes the natural revegetation processes after long-term fluvial deposition of copper tailings. Land Degradation and Development, 29(6), pp. 1915-1924. doi:10.1002/ldr.2921

Smartt, P. F. M. 1978. Sampling for Vegetation Survey: A Flexible Systematic Model for Sample Location. Journal of Biogeography, 5(1). doi:10.2307/3038106

Tischew, S., \& Kirmer, A. 2007. Implementation of Basic Studies in the Ecological Restoration of Surface-Mined Land. Restoration Ecology, 15(2), pp. 321-325. doi:10.1111/j.1526100x.2007.00217.x

Prach, K., \& Walker, L. R. 2011. Four opportunities for studies of ecological succession. Trends in Ecology and Evolution, 26(3), pp. 119-123. doi:10.1016/j.tree.2010.12.007

Walker, L. R. (ed.) 1999. Ecosystems of disturbed ground. Ecosystems of the world, Amsterdam: Elsevier., 16.

Walker, L. R., \& del Moral, R. 2003. Primary Succession and Ecosystem Rehabilitation. Cambridge: Cambridge University Press (CUP). doi:10.1017/cbo9780511615078

Wiegleb, G., \& Felinks, B. 2001. Predictability of early stages of primary succession in post-mining landscapes of Lower Lusatia, Germany. Applied Vegetation Science, 4(1), pp. 518. doi:10.1111/j.1654-109x.2001.tb00229. 